\title{
O PAPEL FUNDAMENTAL DA CIÊNCIA NO RESGUARDO DO DIREITO À SAÚDE NO CENÁRIO PANDÊMICO
}

\author{
Fábio Dias Da Silva ${ }^{1}$, Daniel Merizio Casati ${ }^{2}$ \\ ${ }^{1}$ Universidade Estadual de Londrina - UEL, Londrina, PR, ${ }^{2}$ Universidade do Oeste Paulista - UNOESTE, Presidente \\ Prudente, SP. E-mail: fabiodiasilva@gmail.com
}

\begin{abstract}
RESUMO
Pelo presente estudo foi possível denotar mais uma vez o papel essencial e fundamental da ciência ao resguardo da saúde, onde se verificou que somente pela intervenção da ciência que se obtém resultados à contenção e diminuição dos efeitos decorrentes de determinada doença, tal como a pandemia do coronavírus. Muito embora tenha sido conferido o caráter fundamental da ciência o Estado brasileiro penou em reconhecer esse ramo como indispensável, sendo necessária a vinda de mortes para a busca de uma correta solução para o problema da ciência, levando em consideração que com parcos recursos a ciência conseguiu obter resultados eficazes para a consecução da saúde, com o correspondente da vacina. Partindo da premissa da ciência e seu caráter fundamental o objetivo do presente trabalho foi delinear a abrangência e aplicação desse ramo para com o resguardo do Direito à Saúde, ainda mais quando uma pandemia exige um agir emergencial e urgente para a contenção de seus efeitos. Para a efetiva consecução do pleno desenvolvimento do trabalho foi utilizado o método indutivo, partindo da ciência e seus efeitos aos demais eixos governamentais. Nesse ínterim que, demonstrado o caráter fundamental da ciência para com o resguardo à saúde, é possível chegar a conclusão estrita de que a ciência tem de andar de mãos dadas com a saúde, visto que essa última depende estritamente da primeira, como também os profissionais da saúde ao aplicar os preceitos da ciência ao resguardo da saúde.
\end{abstract}

Palavras-chave: ciência; pandemia; saúde; fundamental.

\section{THE FUNDAMENTAL ROLE OF SCIENCE IN SAFEGUARDING THE RIGHT TO HEALTH IN THE PANDEMIC SCENARIO}

\section{ABSTRACT}

Through this study it was possible to denote once again the essential and fundamental role of science in protecting health, where it was found that only through the intervention of science that results are obtained to contain and reduce the effects resulting from a certain disease, such as the pandemic of coronavirus. Even though the fundamental character of science has been conferred, the Brazilian State struggled to recognize this branch as indispensable, requiring the coming of deaths to search for a correct solution to the problem of science, taking into account that with scarce resources science managed to obtain effective results for achieving health, with the corresponding vaccine. Starting from the premise of science and its fundamental character, the objective of the present work was to outline the scope and application of this branch for the protection of the Right to Health, even more when a pandemic requires an emergency and urgent action to contain its effects. For the effective achievement of the full development of the work, the inductive method was used, starting from science and its effects to other governmental axes. In the meantime that, having demonstrated the fundamental character of science in protecting health, it is possible to reach a strict conclusion that science has to go hand in hand with health, since the latter strictly depends on the former, as well as the professionals of health by applying the precepts of science to safeguarding health.

Keywords: science; pandemic; health; fundamental. 


\section{INTRODUÇÃO}

Com o surgimento de uma nova doença, com desconhecidos efeitos e respaldos econômicos e sociais, advém a intervenção da ciência, de tal sorte que surge como ferramenta indispensável à contenção e minimização das suas consequências, objetivando um futuro para com um problema que reflete em toda sociedade.

Quando esse problema que decorre da doença traz reflexos em todo o globo é preciso que tenha um esforço conjunto de todos os Estados do mundo, com a participação da Organização Mundial da Saúde, afim de que sejam adotadas as medidas necessárias e adequadas, com origem da ciência, para que o problema, e seus efeitos, sejam reduzidos o quanto antes, evitando o pior, que é uma proliferação incontrolável.

Referida doença quando surtir efeitos em todo o globo é classificada como uma pandemia, onde por si só demonstra a maior necessidade da ciência, da utilização de seus métodos, para que se tenha uma resposta rápida, prática, e partir dos conhecimentos obtidos, vislumbrando o maior interesse que é a saúde.

Por esse trilho que se observa uma mudança de panorama não somente do Estado brasileiro, mas de todo o globo para com o essencialismo que a ciência demonstra, sendo que sem a ciência, sem os conhecimentos obtidos dessa, não se poderia nem ao menos ter qualquer chance à uma doença desconhecida, cujos efeitos igualmente são desconhecidos.

A partir do método indutivo, partindo da premissa da ciência e sua aplicação para com os demais ramos da ciência, e também dos efeitos governamentais, como também partindo de pressuposto à concretização da saúde e objetivo particular por parte do Estado, vezes ser um dever estatal a sua consecução.

Assim, o objetivo desse estudo foi ventilar que sem a ciência, como poderá se verificar, não haverá a saúde, e por esse mesmo fato não poderá ser concretizado o Direito à Saúde, permanecendo o Estado em penúria frente ao enfrentamento de crises como a advinda pelas pandemias, e no caso vivenciado desde 2020, o coronavírus.

\section{CIÊNCIA E SUA IMPORTÂNCIA}

Em primeiro plano observa-se que a ciência, tratando de modo abrangente sua conceituação, é aquele ramo em que se buscam respostas aos eventos da vida, seja por base das áreas biológicas, exatas ou até mesmo humanas, evidenciando uma gênese para a consecução de resultados à solução de determinada questão.

A partir do dicionário de Aurélio Buarque de Holanda Ferreira $(2006$, p. 234) há diversas formas e maneiras de dizer o que se trata a ciência, de tal sorte a conceitua-la:

1. Conjunto metódico de conhecimentos obtidos mediante a observação e a experiência. 2. Saber e habilidade que se adquire para o bom desempenho de certas atividades. 3. Informação,

conhecimento; notícia.

Ciências biológicas. As que estudam os seres vivos.

Ciências exatas. Aquelas (como a física, a química, a astronomia) que descrevem e analisam fenômenos de modo quantitativo e segundo suas relações matemáticas muito precisas. Ciências humanas. $O$ conjunto de disciplinas que têm por objeto o ser humano, do passado e do presente, e seu comportamento individual ou coletivo. Ciências naturais. Aquelas (como a biologia, a botânica, a zoologia, a mineralogia, etc.) que têm como objeto o estudo da natureza.

Dado o que se entende por ciência, muito embora se tratem de conceitos extraídos do dicionário, observa-se que aquele que mais se enquadra ao presente estudo é a informação, o conhecimento, a notícia, ante o estudo de determinada área para que um problema seja solucionado da melhor e forma mais contundente e concreta ao resultado esperado.

A ciência, assim, parte de dois pressupostos que, com a devida vênia, pode-se destacar, sendo nada mais do que um problema e o resultado, desde que se tenha como norte que ambos serão obtidos a partir da informação e do conhecimento, partindo igualmente da notícia de outras formas pelas quais fora tratado determinado caso. 
Dentre esses dois pressupostos que ressalta ainda mais a importância, por assim dizer, da ciência para o mundo, vezes que a partir dessa que se terá a consecução de resultados, resultados esses que trazem reflexos diretos para o modo de viver de todo o globo de modo irrestrito, trazendo uma solução aos problemas.

A sua importância, e assim é preciso destacar, se tornou ainda mais aparente no contexto da pandemia do coronavírus (SarS-CoV2), vírus esse que demonstrou a ineficácia de outros setores, tanto público quanto privado, para seu enfrentamento e até mesmo à diminuição de seus efeitos, desde a contenção da contaminação quanto às mortes ocorridas pelos infectados.

De acordo com notícia veiculada no sítio da ICTP (2020) referente ao papel da ciência no combate à pandemia denota-se a importância da ciência ainda mais evidenciada na pandemia:

Nesses momentos, a
ciência é uma das
principais aliadas para
definir estratégias de
combate à doença, seja
para prever seus impactos
em comunidades ou
climas diferentes, seja
para elaborar modelos de
proteção econômica, ou
para entender melhor o
patógeno na busca de
tratamentos que possam
contê-la.

Como já observado anteriormente a ciência parte dos princípios da informação, do conhecimento e da notícia, envolvendo essas 03 (três) concepções ao enfrentamento de determinada doença, como no caso do coronavírus, trazendo uma proteção econômica, definir estratégias para que seja contida.

Em outras palavras, a ciência é, e assim deve ser tratada, como uma aliada à contenção de doenças, sendo que sua importância é, por si só, relevante e demonstra que somente a partir da ciência, do estudo, do conhecimento, da informação, é que se obtém um resultado adequado e esperado à determinado problema.

Ao trazer a concepção defendida se observa que o problema, muitas das vezes, guarda relação com as ciências biológicas e naturais, trazendo reflexos à vida humana que, de toda sorte, fica à mercê dos avanços da ciência para que seja concretizado o resultado, ao evidenciar uma mudança do paradigma e, também, uma contenção de danos à sociedade em geral.

Não é somente a pandemia do coronavírus que demonstrou e alavancou a importância da ciência, mas, também qualquer evento que necessite de uma resolução, de modo a buscar uma diminuição dos seus efeitos, por exemplo do sarampo, surge a ciência com uma solução - resultado - afim de que suas consequências e efeitos sejam diminuídos, como a partir da criação de uma vacina, adoção de tratamentos a diminuir a contaminação.

Demonstra-se que a ciência surge e atua no fim maior, que é evitar a proliferação de doenças e problemas de tal sorte que pelas suas soluções e seus métodos resultam na prevenção e precaução do mundo como um todo, como ocorrera na pandemia do coronavírus.

Embora seja questão a ser abordada em tópico específico, o que se verifica é que a ciência evolui de uma maneira em que o ser humano deve acompanhar e para isso que torna ainda mais evidente sua importância, haja vista que sozinha a ciência nada fará se não houver a conscientização de todos do seu caráter fundamental.

Exemplo disso se dá quando, alheio à importância que a ciência detém para todos os seres humanos, as pessoas param de se vacinar, sob a justificativa de que determinada doença não mais existe, revivendo uma doença que estava praticamente erradicada, se não fosse a ignorância do próprio ser humano.

Em matéria publicada por Adriane Cruz (2017) junto à Fio Cruz:

Até chegar aos cidadãos, as vacinas passam por um rigoroso processo de produção, começando com estudos e pesquisas, passando por inúmeros testes até ser validada e disponibilizada nos postos de saúde. Esse esforço também passa pelos gestores da saúde, responsáveis pela distribuição dos imunizantes e pela preparação dos profissionais de saúde para a aplicação da vacina. Apesar dos números inegáveis que demonstram a eficácia e 
importância da vacina, cresce 0 número de pessoas que se recusam a vacinar seus filhos, fomentando um movimento perigoso que pode trazer de volta doenças como o sarampo e a poliomielite.

As vacinas, símbolo concreto e tateável do avanço da ciência, demonstra a importância da ciência para a sociedade em geral, vezes que por meio dessa passa um rigoroso processo de produção, inúmeros testes até ser disponibilizada, e esse processo todo não surge somente para com aqueles que criaram e participaram da contenção de determinada doença, mas, sim, para todo contexto, como para com os gestores de saúde, setores esses que se englobam e se envolvem para que a ciência seja trazida às pessoas.

Evidente que a ciência, e todos os meios nos quais ela se apresenta, é de caráter essencial e de nítida importância para a contenção e disseminação de doenças tal como o coronavírus, sendo que seu caráter de importante não mais se tornou inequívoco como atualmente.

A importância da ciência não advém da contenção do coronavírus, ou até mesmo de seus efeitos, mas, advém ao longo dos anos, a partir da evolução da própria ciência na consecução de um resultado, buscando uma solução que faz com que o mundo veja a ciência como deve ser vista, indispensável à solução dos mais vastos problemas enfrentados, o que não poderia ser diverso com o coronavírus.

\section{DIREITO À SAÚDE NO CONTEXTO PANDÊMICO}

O direito a saúde, como tratado na Constituição da República de 1988, é tido como um direito de todos e um dever do Estado, não sendo demais destacar o teor do artigo 196 o qual dispõe que "a saúde é direito de todos e dever do Estado, garantido mediante políticas sociais e econômicas que visem à redução do risco de doença e de outros agravos e ao acesso universal e igualitário às ações e serviços para sua promoção, proteção e recuperação.".

Dessa redação é possível identificar o destinatário do Direito à Saúde, bem como os fins pelos quais deve ser aplicado referido direito, haja vista a sua oponibilidade a todos, afim de que sejam reduzidos os riscos de doença e de outros agravos, estabelecendo seu caráter universal e igualitário, tanto das ações quanto para os serviços necessários à sua consecução.

Com base na redação da Magna Carta se observa que está inserido dentre os direitos sociais que, de acordo com Luiz Alberto David Araujo e Vidal Serrano Nunes Júnior (2009, p. 218) "[...] são aqueles que reclamam do Estado um papel prestacional, de minoração das desigualdades sociais.".

Pelo reforço da doutrina ao já previsto na Constituição da República de 1988 se extrai que o Direito à Saúde, como Direito Social que é concretiza que todos, independentemente da sua condição financeira ou até mesmo condição social, detêm do direito de exigir por parte do Estado que seja garantida à saúde, mormente por políticas públicas a reduzir os riscos de doença.

E essas ações por parte do Estado devem ser voltadas à promoção do bem da sociedade, pensando tanto no interesse individual de cada um para com o interesse voltado a todos, de tal sorte a tutelar de forma igualitária e resguardar o direito à saúde de todos.

Nesse viés Gilmar Ferreira Mendes e Paulo Gustavo Gonet Branco (2016, p. 686) lecionam:

Numa visão geral, o direito à saúde há de se efetivar mediante ações específicas (dimensão individual) e mediante amplas políticas públicas que visem à redução do risco de doença e de outros agravos (dimensão coletiva). Nessas perspectivas, as pretensões formuladas e formuláveis tanto poderão dizer respeito a atos concretos como a políticas e ações administrativas que contribuam para a melhoria do sistema de saúde, incluídas aqui as normas de organização e procedimento.

O âmbito de abrangência do direito à saúde contém não somente à determinada questão particular, o que pode ser entendida com questão individual, mas detém igualmente da redução do risco de doenças, e isso se entende por risco de doenças que poderá afetar a coletividade, guardando respaldo para questões 
coletivas. O Direito à saúde englobaria tanto o interesse individual quanto o coletivo.

Entretanto, essas ações não são irrestritas, de tal sorte que devem ser adotadas sem qualquer critério ou até mesmo sem qualquer limite, vezes que por se tratar de dinheiro público, indisponível, devem ser tratadas com a cautela que é necessária quando se trata de políticas públicas a fomentar o direito à saúde.

A questão dos recursos destinados à saúde já foi matéria enfrentada pelo Ministro Luis Roberto Barroso, em seu voto do Recurso Extraordinário o 566.471, do Rio Grande do Norte:

\begin{abstract}
Nesse contexto, a escassez de recursos traz contornos dramáticos às decisões alocativas na área da saúde. Afinal, como definir quais prestações fornecer? Quanto destinar ao orçamento da saúde? Quais tratamentos e pacientes priorizar? Como é natural, todas essas indagações devem ser pensadas e respondidas pelos órgãos competentes para a elaboração das políticas públicas de saúde. $E$ não pelo Judiciário. [...] (BARROSO, [2000?].
\end{abstract}

Como observado quando há a judicialização do Direito à Saúde, seja para obrigar o Estado a fornecer determinado medicamento ou procedimento, seja para determinar que o Estado cumpra suas obrigações, porém, o que se observa é que há uma escassez de recursos dirigidos à saúde, vezes que ou foram desviados da sua finalidade ou pela distribuição orçamentária não houve previsão adequada às necessidades da saúde.

Há de se ter em vista que não é possível que se tenha grandes dispêndios de valores, de forma irrestrita, com a promoção da saúde. Contudo, o que se observa é o contrário, ou seja, a justificativa por parte do Estado que não detém de condições econômico-financeiras para suportar o custeio do Direito à Saúde.

Ao se adotar a concepção de que o Direito à Saúde é um dever do Estado, dever esse que se estende em ações a evitar a proliferação de doenças, englobando nesse ínterim o interesse individual, a partir das necessidades pessoais, resguardadas as suas próprias limitações, por se tratar de interesses da coletividade e igualmente relacionados ao erário público, em qualquer cenário pandêmico, como o vivido em decorrência do coronavírus, resta ainda mais incontroverso o dever estatal de realizar a contenção dessa doença.

$E$, por se tratar de uma pandemia, em que se exige medidas emergenciais e mais enérgicas por parte do Estado, há o interesse primordial do resguardo à saúde por parte do Estado, evidenciando ainda mais o dever estatal de prestar a saúde a todos, e desse modo de forma e maneira a minimizar os efeitos que a doença vier a ocasionar.

Tal como afirmado e já enfrentado pelo Supremo Tribunal Federal sobre a escassez de recursos dirigidos à saúde, ou até mesmo a sua limitação, tem-se que essa imagem muda de figura quando se trata de uma pandemia, passando a ter como objetivo primordial o resguardo da saúde de todos, relativizando-se, assim, direitos, prevalecendo a saúde de todos, vezes que o que em pandemias o que se resguarda é a vida, consequentemente a saúde.

Se houver, no cenário pandêmico, outra limitação, outro objetivo a não ser a saúde, prevalecendo a vida das pessoas, haverá um consequente desbalanceamento da moralidade e dos fundamentos da República Federativa do Brasil de 1988, cujo fim maior é o resguardo da dignidade da pessoa humana.

O sentido de não limitar o âmbito de abrangência do direito à vida foi objeto de fundamento para a decisão liminar do Ministro Alexandre de Moraes quando da apreciação do pedido na ADI 6357:

[...] O direito à vida e à saúde aparecem como consequência imediata da consagração da dignidade da pessoa humana como fundamento da Re-pública Federativa do Brasil. Nesse sentido, a Constituição Federal consagrou, nos artigos 196 e 197, a saúde como direito de todos e dever do Estado, garantindo sua universalidade e igualdade no acesso às ações e serviços de saúde. A 
gravidade da emergência causada pela pandemia do COVID-19

(Coronavírus) exige das autoridades brasileiras, em todos os níveis de governo, a efetivação concreta da proteção à saúde pública, com a adoção de todas as medidas possíveis para o apoio e manutenção das atividades do Sistema Único de Saúde. $O$ desafio que a situação atual coloca à sociedade brasileira e às autoridades públicas é da mais elevada gravidade, e não pode ser minimizado. A pandemia de COVID-19 (Coronavírus) é uma ameaça real e iminente, que irá extenuar a capacidade operacional do sistema público de saúde, com consequências desastrosas para a população, caso não sejam adotadas medidas de efeito imediato, inclusive no tocante a garantia de subsistência, empregabilidade e manutenção sustentável das empresas. [...] (grifo nosso) (BRASIL, 2020)

A decisão do Supremo Tribunal Federal nada mais faz do que estabelecer um parâmetro ilimitado para com o Direito à Saúde quando se tratar de pandemia, o qual levou em consideração a gravidade do cenário pandêmico e a necessidade de condutas efetivas à proteção da saúde pública, o que demonstra que o dinheiro, seja ele público ou privado, não detém de qualquer sentido se não houver o resguardo da saúde.

E é nesse parâmetro que o Direito à Saúde, tal como contextualizado pela doutrina, quanto pela Constituição da República de 1988, como também pela jurisprudência, deve ser trazido, sendo que o interesse maior não é o dinheiro em si, mas, sim, a saúde, pois sem saúde, condição necessária para desfrutar de todos direitos, não será possível verificar se houve algum desvio do erário público, tendo em vista que nada existirá sem saúde.

Uma pandemia, ou até mesmo a pandemia do coronavírus, exige por parte do Estado medidas nunca jamais vistas, haja vista o ineditismo que esse cenário nos traz, relativizando direitos e tornando outros direitos, como o Direito à Saúde, prioritários. Não se defende o esquecimento dos demais direitos, mas, sim, que se tenha um filtro para com os direitos, prevalecendo aqueles que mais necessitam de proteção e tutela do que aqueles não tão afetados por uma pandemia.

Por assim ser verifica-se que há uma limitação de direitos, não podendo esses direitos serem utilizados como escudo para ilegalidades e irregularidades, porém, em se tratando de um cenário pandêmico, foge-se da normalidade, do que é esperado, necessitando e exigindo por parte do Estado outra conduta que não aquela dentro da normalidade, evidenciando o caráter excepcional.

\section{PAPEL FUNDAMENTAL DA CIÊNCIA NA PANDEMIA}

A ciência, como já é sabido, é indispensável e essencial à consecução de resultados práticos e contundentes sobre suas diversas áreas, como é tratado nesse trabalho da área da saúde, correspondendo à um resultado ao problema da pandemia, sendo que esse problema igualmente poderia ser uma doença, evidentemente demonstrando uma solução por parte dos pesquisadores acerca de qual caminho percorrer.

Em tempos de pandemia, como a vivenciada pelo coronavírus, há a incessante busca para tratamentos, dados que possam auxiliar os setores da saúde para que possam caminhar, e até mesmo uma solução definitiva que se dá a partir da vacina, ainda mais por se tratar de algo novo, nunca jamais vivido e enfrentado.

E é nesse sentido que se demonstra ainda mais a importância da ciência para a contenção de doenças, vezes que somente pela ciência que se detém de resultados acerca de qual caminho a ser traçado.

Em artigo publicado pelo IPEA - Centro de Pesquisa em Ciência, Tecnologia e Sociedade, de autoria de Fernanda De Negri et al. (2020), tem destacado o papel fundamental da ciência na pandemia: 
Por se tratar de uma doença e de uma situação novas, as lacunas de informação e conhecimento ainda são muito grandes: taxas de letalidade, potencial de transmissão, tratamento, existência de outros efeitos ou sequelas no organismo dos que foram infectados, todas essas informações ainda são preliminares.

Nesse momento, a produção científica é crucial para melhor compreender a doença e seus efeitos e buscar soluções. Pesquisadores e cientistas, no mundo todo, em muitos casos a partir de uma boa coordenação governamental, estão se mobilizando para estimar tanto os efeitos da doença sobre a saúde da população quanto os impactos econômicos e sociais dessa pandemia. [...]( NEGRI et al., 2020).

A ciência, quanto à pandemia, atuará não somente na produção de soluções, mas, também, na busca dos efeitos pelos quais a doença que decorreu a pandemia trará sobre a população, seus impactos econômicos e sociais, englobando e tratando informações, e principalmente conhecimento, afim de conter e remediar as consequências, ainda mais quando se evidencia que é uma doença letal e com alto índice de mortalidade.

Além da busca de soluções para que se tenha uma contenção ou até mesmo uma redução dos índices de mortalidade, bem como de tratamento, demonstra-se que pela ciência, daí o seu caráter fundamental, se buscará desvendar o novo, o que é desconhecido, clareando as ações de todos os setores da economia e, também, do governo.

A Organização Mundial da Saúde, ao sentir a necessidade de um esforço mútuo entre o globo todo, estabeleceu um caminho a ser traçado, definindo prioridades e igualmente definindo que o governo deve acelerar as pesquisas para contribuir à contenção da pandemia, além de determinar o foco para que se tenha a pesquisa.

De acordo com o sítio da Organização Mundial da Saúde (2020), em cartilha publicada, resultante de um fórum realizado em fevereiro de 2020, destacam-se as seguintes prioridades quanto à pandemia do coronavírus:

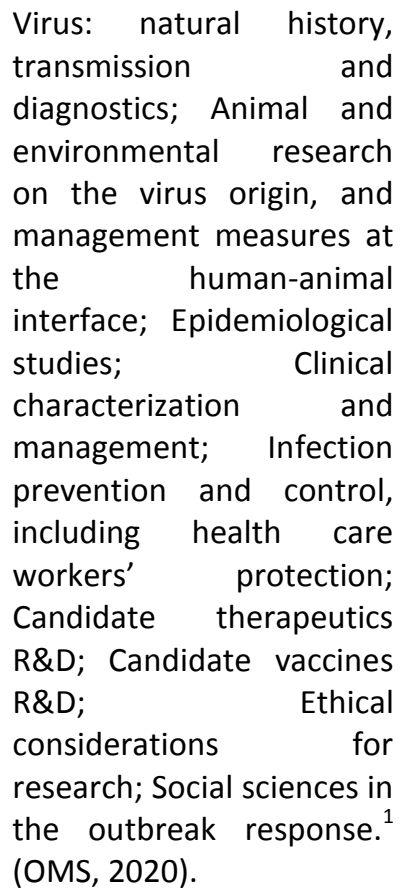

É também de conhecimento e preocupação do órgão máximo da saúde dos efeitos pelos quais a pandemia trará desde aos infectados, até mesmo aos profissionais da saúde quando tratarem os enfermos, chegando até nas respostas quanto ao ambiente em que o vírus está inserido e igualmente onde esteve.

E essas respostas somente sobrevieram nos dias atuais com a pesquisa, denotando ainda mais o seu caráter fundamental, pois, se não houvesse o papel ativo e forçoso da ciência, não teria qualquer resultado quanto à contenção e enfrentamento da pandemia do coronavírus.

Cabe ressaltar que o papel fundamental da ciência demorou a ter sido considerado como prioridade ao enfrentamento da pandemia, muito embora tenha, no íntimo e nos seus próprios e únicos esforços, trazidos rumos diferentes à pandemia do coronavírus.

Utiliza-se, para esse fim, o brocardo utilizado de que "a ciência venceu", para

\footnotetext{
${ }^{1}$ Vírus: história natural, transmissão e diagnóstico; Pesquisas em animais e no ambiente de origem do vírus e medidas de manejo na interface homem-animal; Estudos epidemiológicos; Caracterização clínica e manejo; Prevenção e controle de infecções, incluindo a proteção dos profissionais de saúde; candidato a terapias na $P \& D$; candidato a vacina na P\&D; Considerações éticas para pesquisa; Ciências sociais na resposta ao surto. (tradução nossa)
} 
demonstrar que há muito tempo a ciência vem enfrentando obstáculos orçamentários, baixo incentivo de pessoal e, mesmo assim, trouxe resultados inequívocos e indispensáveis ao enfrentamento da pandemia do coronavírus.

A queda no financiamento da pesquisa e até mesmo a falta de previsão de orçamento dirigido à pesquisa vale como fundamento para que os pesquisadores desanimem e temem pelo rumo da ciência, tendo em vista que, além de não ser barata, depende, e muito, de incentivo público.

Breiller Pires (2020), em artigo publicado no sítio EL PAÍS retrata a questão da carência de recursos da ciência e trazida ainda mais à tona quanto a pandemia do coronavírus:

$$
\begin{aligned}
& \text { Boletim epidemiológico, } \\
& \text { carga viral, curva de } \\
& \text { infectados, média } \\
& \text { móvel, imunidade de } \\
& \text { rebanho, cobertura } \\
& \text { vacinal... Por causa } \\
& \text { da pandemia de } \\
& \text { coronavírus, termos } \\
& \text { técnicos, geralmente } \\
& \text { restritos ao universo dos } \\
& \text { infectologistas, passaram a } \\
& \text { fazer parte do cotidiano } \\
& \text { de milhões de brasileiros. } \\
& \text { A ciência nunca esteve tão } \\
& \text { em evidência como agora, } \\
& \text { mas, por outro lado, } \\
& \text { jamais havia sido tão } \\
& \text { esnobada por governantes } \\
& \text { e uma parcela da } \\
& \text { população que preferem } \\
& \text { relativizar a gravidade da } \\
& \text { crise sanitária mundial. } \\
& \text { Enquanto a vacina demora } \\
& \text { a se tornar uma } \\
& \text { realidade no Brasil, } \\
& \text { acadêmicos e cientistas } \\
& \text { viram o ano apreensivos } \\
& \text { com o futuro das } \\
& \text { pesquisas e a perspectiva } \\
& \text { de redução de } \\
& \text { investimentos em } \\
& \text { trabalhos científicos nas } \\
& \text { universidades públicas. } \\
& \text { [...] (PIRES, 2020), }
\end{aligned}
$$

Por um lado, a ciência vem ganhando relevância, e demonstrando ainda mais seu caráter fundamental ao enfrentamento de doenças e da pandemia do coronavírus, onde por outro lado o governo, fala-se de um modo geral, visto que tanto os governos estaduais quanto $o$ federal estão realizando cortes na pesquisa, não oferecendo qualquer respaldo e incentivo, o que por si só demonstra o trabalho somente de uma das partes, que é a ciência.

O que se observa é que o Estado pede por soluções que somente a ciência traz, mormente para com as doenças e pandemia, porém, não traz $o$ incentivo necessário e adequado que se espera e que é exigido, ainda mais em se tratando de trabalhos que necessita, querendo ou não, de recursos financeiros.

Não é objeto desse estudo, mas é preciso repugnar a falta de incentivo para com a ciência, sendo que ainda mais nos dias de hoje se demonstrou fundamental ao enfrentamento de toda e qualquer doença, ainda mais as desconhecidas e novas como o coronavírus, evidenciando o único caminho que é a ciência.

A própria ciência necessita ser reconhecida como fundamental que é, não somente para com as pandemias, doenças, mas em geral, haja vista que essa traz estudos, conhecimentos, informações, necessárias ao enfrentamento de determinado problema, buscando soluções concretas e contundentes que não pode ser deixada de lado a qualquer momento, ainda mais quando se fala em reflexos no mundo inteiro.

\subsection{A ciência como ferramenta à consecução do direito à saúde na pandemia}

Pelo que se observou no contexto da ciência, e seu caráter fundamental à obtenção de resultados para o enfrentamento da pandemia, temos que essa igualmente traz reflexos quanto ao Direito à Saúde, direito esse que deve ser resguardado e observado ainda mais no contexto de uma pandemia que assola todo o mundo.

Ao tratar do Direito à Saúde ensina José Afonso da Silva (2004, p. 307) quanto aos seus vieses:

[...] E há de informar-se pelo princípio de que o direito igual à vida de todos os seres humanos significa também que, nos casos de doença, cada um tem o direito a um tratamento condigno de acordo com o estado atual da ciência médica, independentemente de sua situação econômica, sob pena de não ter muito valor sua consignação em 
normas constitucionais. (grifo nosso) (SILVA, 2004, p. 307)

Pelo enfoque trazido observa-se que o direito à saúde, direito inerente a todos, e um dever do estado, guarda estrita relação com o estado atual da ciência médica, demonstrando ambos são dependentes, onde pelo avanço da ciência médica que se resguardará o Direito à Saúde, direito esse inerente a todos os procedimentos, todas as condutas médicas necessárias para conter determinada doença.

Em outras palavras, os tratamentos, procedimentos, todo e qualquer ato relacionado ao direito à saúde estará ligado à ciência médica, sendo que essa ditará os rumos pelos quais será resguardado esse direito de todos e um dever do Estado.

Como destacado no tópico anterior a ciência vem tendo dificuldades em manter suas pesquisas na busca de informações, conhecimentos adequados, mormente em razão da falta de recursos econômico-financeiros, por meio de incentivos, o que traz reflexos diretos quanto à consecução do direito à saúde, vezes que a ciência e esse direito estão intimamente ligados.

Nesse contexto enfoca Gilmar Ferreira Mendes e Paulo Gustavo Gonet Branco (2016, p. 686):

[...] É incontestável que, além da necessidade de se distribuírem recursos naturalmente escassos por meio de critérios distributivos, a própria evolução da medicina impõe um viés programático ao direito à saúde, pois sempre haverá uma nova descoberta, um novo exame, um novo prognóstico ou procedimento cirúrgico, uma nova doença ou a volta de uma doença supostamente erradicada. (BRANCO, 2016, p.686)

As políticas públicas, inseridas no contexto social e econômico, devem ser voltadas ao Direito à Saúde, e consequentemente resguardada a própria evolução da medicina, que se dá através da ciência, onde se verificará uma nova descoberta, um novo procedimento, como também uma nova doença como o coronavírus.

Partindo desse princípio em que é necessário ter a distribuição de recursos naturalmente escassos, haja vista até mesmo que o Estado vem restringindo o incentivo para com a ciência, ainda mais se torna essencial esse ramo para o resguardo do Direito à Saúde, mormente na pandemia vivenciada.

Devem ser despendidos todos os esforços necessários e à disposição do Estado a incentivar a ciência, vezes que essa é a ferramenta adequada à consecução do Direito à Saúde, sendo que não pode o entrave governamental servir de fundamento para a não contenção da proliferação desse vírus.

Como já enfatizado pelo Ministro Alexandre de Moraes quando da decisão do pedido liminar na ADI 6357 o Estado Brasileiro, ante a existência de uma doença nova, uma situação jamais vivida, deve adotar todas medidas possíveis, vezes que o interesse maior está na vida, na saúde de todos, deixando de lado todos os demais direitos em detrimento de um.

Deve ser buscada a efetividade da norma constitucional que, na concepção de Luís Roberto Barroso (1996, p. 220) "ela representa a materialização, no mundo dos fatos, dos preceitos legais e simboliza a aproximação, tão íntima quanto possível, entre o dever-ser normativo e o ser da realidade social.".

A contextualização e materialização do Direito à Saúde não guarda somente relação com a ciência, mas, em se tratando de medidas extremas, como a pandemia do coronavírus, se exige uma efetividade, e também a busca por uma efetividade, da norma constitucional, deixando de lado os preceitos estanques, como as limitações orçamentárias, para o fim maior aos seres humanos.

Levando em consideração a efetividade da norma constitucional descrita no Direito à Saúde, de tal forma a adotar os parâmetros e ações necessárias à consecução desse direito, é possível denotar que a ciência serve de critério máximo para adoção de novos tratamentos, procedimentos, à contenção da pandemia.

E esses novos tratamentos, por se tratar de uma doença nova e, também, crua quanto aos modos de contenção de seus efeitos, exige por parte dos profissionais de saúde a adoção de tratamentos porventura experimentais e relacionados à outras enfermidades e doenças 
que já anteriormente existiam, vezes não haver um consenso quanto ao seu tratamento.

Questão que surge é em relação à forma da prática dos procedimentos aplicados e avançados pela ciência pelos profissionais da saúde, o que demonstra a questão que, mesmo se tratando de doença nova, são adotados procedimentos novos e jamais vistos, ante o ineditismo que o coronavírus detém, por exemplo.

Os profissionais da saúde há muito são vistos como os primeiros a enfrentar os efeitos da pandemia, a despeito do parco incentivo à ciência, estando na linha de frente a resguardar o Direito à Saúde, enquanto não seja totalmente imunizada a população a partir das vacinas, instrumento máximo à contenção de doenças.

Cabe trazer os ensinamentos de Miguel Kfouri Neto (2003, p. 36):

[...] o ser humano está sujeito às doenças, ao sofrimento - e toda tentativa que vise a suprimir a culpa conduz à transformação da prestação devida pelos médicos, tão-só, em obrigação de resultado -, o que de modo nenhum se torna aceitável. A dor, a doença, a morte, as alterações da saúde não constituem, em princípio, um risco que nasça da atividade médica, mas algo ínsito ao ser humano - e cada médico em particular e o conjunto deles, em todo o mundo, busca aliviar esse sofrimento, remediar a enfermidade e restaurar a saúde. O próprio doente traz consigo um risco, derivado da sua patologia - e não é o médico quem o provoca. Adotar uma responsabilidade objetiva, nesse caso, equivale a lutar contra a própria natureza humana. Dar cobertura a todo risco de doença ou morte, em atividade médica, corresponderia a obrigar o médico a dar a saúde ao doente, a prolongar a vida, ultrapassando

as

potencialidades do médico enquanto homem, para transformá-lo num Deus. (KFOURI NETO, 2003, p. 36).

O enfoque da doutrina é necessário principalmente em razão do caráter fundamental que a ciência detém, tendo em vista que os profissionais da saúde, por exemplo, não podem ser responsabilizados, ou até mesmo levados à punição, em razão de uma doença nova em que nem ao menos há consenso quanto ao seu tratamento e formas de enfrentamento.

A observação serve de medida a readequar o Direito à Saúde, tendo em vista que por se tratar de uma doença nova, decorrente do coronavírus, a ciência servirá essencialmente de ferramenta à consecução desse direito, não podendo nascer uma forma de responsabilidade pelo que é novo.

É salutar que a ciência trará um norte a ser seguido aos profissionais da saúde que, por óbvio, agem para resguardar o Direito à Saúde, devendo não só o incentivo ser para com a ciência, mas também aos profissionais que fazem valer o Direito à Saúde, nesse caso inserido os médicos, enfermeiros, enfim, todo profissional de saúde na linha de frente à contenção da pandemia.

Deste modo que se observa que a ciência é sim ferramenta indispensável e fundamental à consecução do Direito à Saúde, direito esse que é resguardado pelos profissionais da saúde que nada mais fazem do que estabelecer um parâmetro de tratamento baseado em doenças similares, ante o desconhecido.

Ainda assim o Estado não deve se desvencilhar ou até mesmo fechar os olhos quanto às necessidades e às condutas exigidas à contenção de uma pandemia, se for necessário ao resguardo da vida humana, pela situação jamais vivida, é evidente a adoção de novas condutas.

\section{CONCLUSÃO}

Pelo tudo que foi exposto é forçoso concluir que sem a ciência de nada seria o ser humano frente à pandemia ou até mesmo para a contenção de qualquer doença, haja vista que somente com a ciência que se pode obter resultados concretos à consecução e objetivação 
do Direito à Saúde, direito esse inerente a todos e igualmente um dever do Estado.

Ainda nesse ponto observou-se que 0 Direito à Saúde como um dever do Estado se vincula intimamente com a ciência, de tal sorte que somente com essa última que poderá o Estado concretizar seu dever de fornecer a saúde a todos, sendo que o avanço trazido pela ciência, através de novos procedimentos, tratamentos, respalda diretamente a saúde e também vincula os profissionais da saúde que, baseados na ciência e na sua evolução, farão com que o Direito à Saúde seja abrangido a todos.

Ainda nesse ponto se obtém por concreto que a ciência é fundamental à contenção e enfrentamento de doenças, sendo que ainda mais se vislumbrou que a ciência é ferramenta essencial para se conter uma pandemia que aflige todo o globo, minimizando seus efeitos e trazendo aos governos um norte a ser seguido, mormente quando se trata de uma doença com tamanha mortalidade como a do coronavírus.

Por assim ser a ciência é fundamental para todo e qualquer ramo e área, sendo que somente pela ciência que se obtém resultados práticos, concretos à consecução do Direito à Saúde, onde o Estado está ainda mais dependente de seus avanços para que possa traçar um percurso ideal e adequado.

\section{REFERÊNCIAS}

ARAUJO, L. A. D.; NUNES JÚNIOR, V. S.. Curso de direito constitucional. 13. ed. São Paulo: Saraiva, 2009.

BARROSO, L. R. Medicamentos de alto custo. Luís Roberto Barroso Jurisdição Constitucional e Debates Públicos. [2000?]. Disponível em: https://luisrobertobarroso.com.br/wpcontent/uploads/2016/10/RE-566471Medicamentos-de-alto-custo-versa\%CC\%83ofinal.pdf. Acesso em: 04 ago. 2021.

\section{BARROSO, L. R. Interpretação e aplicação da} constituição: fundamentos de uma dogmática constitucional transformadora. São Paulo: Saraiva, 1996.

BRASIL. Constituição (1988). Constituição da República Federativa do Brasil. Brasília: Senado Federal, 1988. Disponível em: http://www.planalto.gov.br/ccivil_03/constituica o/ConstituicaoCompilado.htm. Acesso em: 05 ago. 2021.
BRASIL. Supremo Tribunal Federal. ADI 6357. Requerente: Presidente da República. Relator: Ministro Alexandre de Moraes. Brasília, DJE, 2020. Disponível em:

http://portal.stf.jus.br/processos/downloadPeca. asp?id=15342780618\&ext=.pdf. Acesso em: 04 ago. 2021.

NEGRI, F. et al. Ciência e tecnologia frente à pandemia: como a pesquisa científica e a inovação estão ajudando a combater o novo coronavírus no Brasil e no mundo. Instituto de Pesquisa Econômica Aplicada. Brasília, 27 mar. 2020. Disponível em:

https://www.ipea.gov.br/cts/pt/central-deconteudo/artigos/artigos/182-corona\#_edn1. Acesso em: 05 ago. 2021.

CRUZ, A.. A queda da imunização no Brasil. Revista Consensus, out./ dez. 2017. Disponível em:

https://portal.fiocruz.br/sites/portal.fiocruz.br/fil es/documentos/revistaconsensus_25_a_queda_d a_imunizacao.pdf. Acesso em: 04 ago. 2021.

FERREIRA, A. B. de H.. Miniaurélio : o dicionário da língua portuguesa. 6. ed. Curitiba: Positivo, 2006.

ICTP. South American Institute for Fundamental Research. $\mathbf{O}$ papel da ciência no combate à pandemia. São Paulo: Universidade Estadual Paulista, 2020. Disponível em: https://www2.unesp.br/portal\#!/noticia/35651/o -papel-da-ciencia-no-combate-a-pandemia. Acesso em: 04 ago. 2021.

KFOURI NETO, M. Responsabilidade civil do médico: à luz do novo Código Civil, com acréscimo doutrinário e jurisprudencial. 5. ed.. São Paulo: Revista dos Tribunais, 2003.

MENDES, G. F.; BRANCO, P. G. G. Curso de Direito Constitucional. 11. ed. São Paulo: Saraiva, 2016.

PIRES, B. Ciência brasileira sofre com cortes de verbas e encara cenário dramático para pesquisas em 2021. El Pais, dez., 2020. Disponível em: https://brasil.elpais.com/brasil/2020-12-

$31 /$ ciencia-brasileira-sofre-com-cortes-de-verbase-encara-cenario-dramatico-para-pesquisas-em2021.html. Acesso em: 05 ago. 2021. 
SILVA, J. A. da. Curso de direito constitucional

positivo. 32. ed. São Paulo: Malheiros, 2009.

WHO. WORD HEALTH ORGANIZATION. COVID 19

public health emergency of international

concern (PHEIC). 2020. Disponível em:

https://www.who.int/blueprint/priority-

diseases/key-

action/Global_Research_Forum_FINAL_VERSION

_for_web_14_feb_2020.pdf?ua=1. Acesso em: 05

ago. 2021. 